ORIGINAL ARTICLE

\title{
Medical intelligence in Sweden. Vitamin B12: oral compared with parenteral?
}

\author{
M Nilsson, B Norberg, J Hultdin, H Sandström, G Westman, J Lökk
}

Postgrad Med J 2005;81:191-193. doi: 10.1136/pgmj.2004.020057

See end of article for authors' affiliations

.....................

Correspondence to:

Dr B Norberg, Department

of Internal Medicine,

University Hospital of

Northern Sweden, SE-901

85 Umeå, Sweden:

bo.norberg@vll.se

Submitted 5 February 2004

Accepted 22 April 2004
Background: Sweden is the only country in which oral high dose vitamin B12 has gained widespread use in the treatment of deficiency states.

Objective: The aim of the study was to describe prescribing patterns and sales statistics of vitamin B12 tablets and injections in Sweden 1990-2000.

Design, setting, and sources: Official statistics of cobalamin prescriptions and sales were used.

Results: The use of vitamin B12 increased in Sweden 1990-2000, mainly because of an increase in the use of oral high dose vitamin B12 therapy. The experience, in statistical terms a "total investigation", comprised 1000000 patient years for tablets and 750000 patient years for injections. During 2000, $13 \%$ of residents aged 70 and over were treated with vitamin B12, two of three with the tablet preparation. Most patients in Sweden requiring vitamin B12 therapy have transferred from parenteral to oral high dose vitamin B12 since 1964, when the oral preparation was introduced.

Conclusion: The findings suggest that many patients in other post-industrial societies may also be suitable for oral vitamin B12 treatment.
$\mathrm{V}$ itamin B12 deficiency may be treated with oral high dose vitamin B12 as effectively as with injections of vitamin B12. ${ }^{1}$ This fact, in practice thought to be "medicine's best kept secret", ${ }^{33}$ was confirmed for American conditions 1998. ${ }^{4}$ The efficacy of oral high dose vitamin B12 has also been confirmed by British and French clinicians. ${ }^{56}$ The only country with widespread experience of oral high dose vitamin B12 in clinical practice is Sweden, where oral preparations have been available in clinical routine from 1964.

The aim of this study is to describe the patterns of vitamin B12 prescriptions and sales in Sweden 1990-2000. It is assumed that such parameters reflect the evaluation of the prescribers, mainly general practitioners (GPs)—a negligible quantity of oral high dose vitamin $\mathrm{Bl} 2$ was sold over the counter without prescription during the period studied $(<1 \%)$.

\section{METHODS}

\section{Background of tradition areas}

In Sweden, there is a tension between history (tradition areas) and present organisation of health care (county councils and regions). Present tradition areas ${ }^{7}$ approximately correspond to catchment areas of the dominating university hospitals. The present description uses the concept of "tradition area"; differences of medical praxis are thought to be easier to show in such entities than in administrative entities with mingled traditions.

The county councils of Sweden are responsible for the health care of their residents. The organisation traces back to 1862 and was subject to formal legislation in 1928. In the period 1990-2000, there were 21 county councils, organised in six regions for expensive health care and education.

In contrast with the administrative organisation, informal tradition areas had emerged because of the history of the health care of the country. ${ }^{7}$ The north east area developed from the university hospitals of Uppsala and Stockholm with younger university hospitals in Umeå, Linköping, and Örebro. The west area developed around the university hospital of
Gothenburg. The south Area developed around the university hospitals of Lund and Malmö (fig 1).

\section{Data sources}

Sales statistics were analysed from Swedish Pharmaceutical Data (Läkemedelsstatistik AB, Stockholm, Sweden) and Apoteket AB, (Stockholm, Sweden, the Swedish national supplier of drugs) during the period 1990-2000. The sales statistics covers prescriptions carried out in primary care. The B12 prescription in hospital care was negligible $(2 \%)$. The population figures are from Statistics Sweden (http:// www.scb.se).

\section{Calculations and basic assumptions}

The calculations of vitamin B12 consumption adhere to the assumptions used by Apoteket $\mathrm{AB}$ for their national statistics. Thus, for injections $1 \mathrm{mg}$ of vitamin B12 as hydroxicobalamin (about $80 \%$ of the market) or cyanocobalamin was assumed to correspond to 50 defined daily doses (DDD) of parenteral therapy. For tablets (cyanocobalamin), the DDD of oral high dose vitamin $\mathrm{Bl} 2$ was assumed to be $1 \mathrm{mg}$ (one tablet, brands Behepan, about $80 \%$ of the market, and Betolvex). One patient year is the number of DDDs (tablets) divided by 360 .

\section{Statistics}

To test the internal consistency within the tradition areas (using comparison between the counties of each area) and the differences between the tradition areas, unbalanced analysis of variance was used. The data analysis was generated using SAS/BASE and SAS/STAT software (version 8 , SAS Institute, Cary, NC, USA). This type of analysis of variance was used, as the number of counties varies between the tradition areas.

\section{Facts already known}

Oral high dose vitamin B12 provides an efficient therapy for vitamin B12 deficiency. 


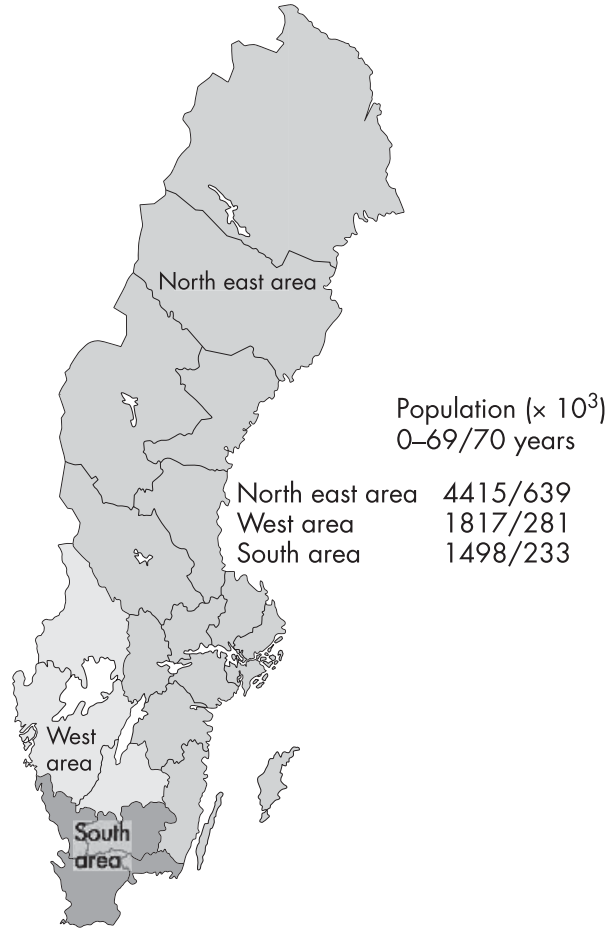

Figure 1 Tradition areas in Sweden.

\section{RESULTS}

\section{Oral high dose vitamin B12 in Sweden}

Physicians in Sweden have gradually gained confidence in oral vitamin B12 since its introduction to the Swedish market in 1964. It is evident from figure 2 that by 1990 oral vitamin B12 therapy was as common as parenteral vitamin B12 therapy. Since then, the balance between the different forms of therapy has moved towards the tablets. The total experience of oral high dose vitamin B12 in Sweden during the period 1990-2000 corresponds to about one million patient years and for parenteral therapy about 750000 patient years. The increase of vitamin B12 sales from 1990 to 2000 could not be explained by an increase of elderly people; residents aged 70 or over only increased by $6 \%$ during the period.

\section{Prescription pattern during $\mathbf{2 0 0 0}$}

Data for 2000 were calculated from the prescription statistics of Apoteket $\mathrm{AB}$, combined with the population statistics of Statistics Sweden. It is estimated that $13 \%$ of the residents aged 70 years and over were treated with vitamin B12, two of three with oral high dose vitamin B12. In the age group below 70 , only $1 \%$ of the people were treated with vitamin

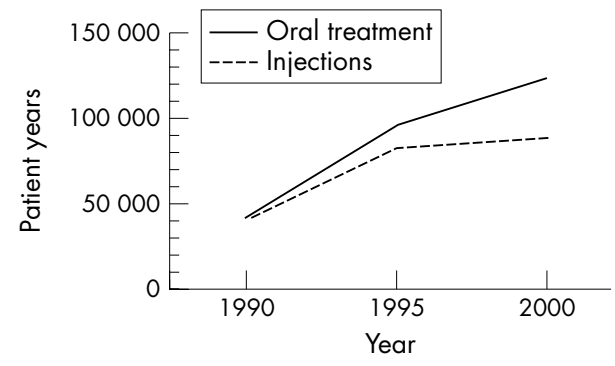

Figure 2 Total sales of vitamin B12 in Sweden 1990-2000 in patient years (all ages). Source: Swedish Pharmaceutical Data.

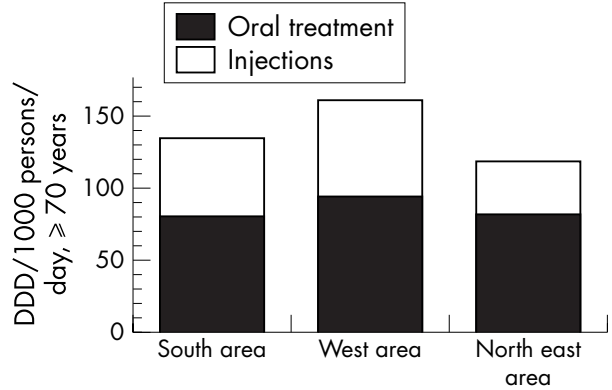

Figure 3 Total prescriptions of vitamin B12 in Sweden in the three tradition areas for residents 70 years and older during 2003. Source: Apoteket AB.

B12, with an equal distribution between tablets and injections.

It is evident from figure 3 that vitamin B12 prescriptions and sales differed in the three tradition areas. The west area had the highest prescription rate of both tablets and injections, the north east area the lowest $(p<0.001)$. In the north east area, $69 \%$ of the total vitamin B12 therapy was oral, compared with $58 \%$ in the west area and $60 \%$ in the south area $(\mathrm{p}<0.001)$. Among residents aged 70 years and over, the fraction treated with vitamin $\mathrm{B} 12$ was $12 \%$ in the north east area, $16 \%$ in the west area, and $14 \%$ in the south area $(\mathrm{p}<0.001)$.

It is obvious from table 1 that the differences seen could not be explained by differences in age and sex between the populations of the three tradition areas. Nor could any internal inconsistency (heterogeneity) in the tradition areas be shown $(\mathrm{p}=0.75)$.

\section{DISCUSSION}

Oral high dose vitamin B12 is registered for both the short term treatment of vitamin B12 deficiency and for maintenance treatment in Sweden. The experience described (figs 2 and 3) suggests that most patients are suitable for tablet regimen, dependent upon patient compliance and physician confidence. The clinical practice of the Swedish physicians studied is based on a high degree of professional knowledge and skill and an intense scientific debate during the past decade..$^{8-11}$ The main limitation of this study is its restriction to prescriptions and sales; no figures of patient compliance are available.

It is reasonable to assume that the increase in the use of oral high dose vitamin B12 in Sweden was promoted by the seven crowns reform $1970 .{ }^{12}{ }^{13}$ The reform provided financial neutrality to the choice between tablet and injection for the physician, the patient, and the producer. However, American, British, and Canadian physicians have argued that oral treatment is cheaper for health care and society. ${ }^{2} 51415$

In Sweden, neurologists and psychiatrists are inclined to prefer injections, at least in the initial stages of deficiency treatment. Most patients prefer tablets, a few injections (fig 2). The prominent use of oral high dose vitamin B12 in the north east tradition area of Sweden is thought to reflect

Table 1 Age and sex distribution in the three tradition areas (female/male, \%)

\begin{tabular}{llll}
\hline Tradition area & $\mathbf{0 - 4 4}$ years & $\mathbf{4 5 - 6 9}$ years & $\geqslant \mathbf{7 0}$ years \\
\hline South & $46 / 49$ & $35 / 37$ & $19 / 14$ \\
West & $46 / 50$ & $35 / 36$ & $18 / 13$ \\
North east & $46 / 49$ & $36 / 37$ & $18 / 13$ \\
\hline
\end{tabular}

Source: Statistics Sweden. 


\section{Learning points}

The study provides 1000000 patient years of oral high dose vitamin B12 therapy in Sweden during the period 1990-2000, compared with 750000 patient years of parenteral therapy. The choice between tablets or injectabiles was approved, monitored, and evaluated by about 10000 GPs, each with their individual bias.

the history of the documentation of oral vitamin B12; the team of Ragnar Berlin worked there. ${ }^{1}$

The main tradition areas formed by history were obvious for those who worked within more than one area. ${ }^{7}$ Despite continuous effort to work towards a consensus, these findings (fig 3) suggest that some differences in prescribing patterns still persist. It is notable that vitamin Bl2 use was lowest in the north east area, where oral vitamin B12 was most popular. Nevertheless, it should be emphasised that the use of vitamin B12 did not exceed the mapping of preclinical deficiency of vitamin B12 and folate in elderly residents of a post-industrial society ${ }^{16}$; vitamin B12 deficiency is mainly a feature of aging. ${ }^{17}$

It is reasonable to assume that the increase in vitamin $\mathrm{B} 12$ treatment from 1990 (fig 2) was attributable to the introduction of homocysteine and methylmalonic acid as deficiency markers in Sweden. The new techniques kindled an intense debate, ${ }^{8-11}$ which improved clinical knowledge and skill. ${ }^{18}$ Findings were compatible with the hypothesis that the laboratory industry was the main sender, supported by pharmaceutical companies with suitable vitamin preparations. The GPs, the predominant prescribers, were main receivers. However, the model is a simplification of a more complex context. ${ }^{8}$

Recent findings confirmed previous experience that vitamin B12 therapy should be combined with folate therapy as a routine precaution. ${ }^{416}$ These vitamins are joined in a series connection in the methionine cycle; lack of substrate (folic acid), blocks the action of coenzyme (vitamin B12), and vice versa. $^{4-1116}$ The Swedish experience suggests that most patients with deficiency could be managed by oral high dose vitamin B12 therapy.

\section{ACKNOWLEDGEMENTS}

MN as principal investigator and BN as principal scientific adviser had full access to study data and take responsibility for the integrity and accuracy of data analyses. All coauthors also had access to data. All authors contributed to interpretation of findings and drafting of manuscript. MN obtained basic data from official statistics and made the preliminary analyses. MN, JL, and HS obtained the funding.

\section{Authors' affiliations}

M Nilsson, B Norberg, Department of Internal Medicine, University Hospital of Northern Sweden, Umeå, Sweden

J Hultdin, Department of Clinical Chemistry, University Hospital of Northern Sweden

H Sandström, G Westman, Department of Family Medicine, University Hospital of Northern Sweden

J Lökk, Department of NEUROTEC, Karolinska Institute/Huddinge Hospital, Stockholm, Sweden

Funding: the study was supported by grants from Stockholm County Council, Karolinska Institute, and Västerbotten County Council.

Competing interests: none declared.

Ethical approval: not required.

\section{REFERENCES}

1 Berlin H, Berlin R, Bramte G. Oral treatment of pernicious anemia with high doses of vitamin B12 without intrinsic factor. Acta Med Scand 1968; 184:247-58.

2 Lederle FA. Oral cobalamin for pernicious anaemia. Medicine's best kept secret? JAMA 1991;265:94-5.

3 Vidal-Alaball J, Butler CC. Critical review: oral high-dose cobalamin? (debate) Rondel 2003;15. http://www.rondellen.net/debate15_eng.htm.

4 Kuzminsky AM, Del Giacco EJ, Allen RH, et al. Effective treatment of cobalamin deficiency with oral cobalamin. Blood 1998;92:1191-8.

5 Nyholm E, Turpin P, Swain D, et al. Oral vitamin B12 can change our practice. Postgrad Med J 2003;79:218-20.

6 Andrés $E$, Perrin A-E, Demangeat $C$, et al. The syndrome of food-cobalamin malabsorption revisited in a department of internal medicine. A monocentric cohort study of 80 patients. Eur J Intern Med 2003;14:221-6.

7 Norberg B. Main medical traditions of Sweden. In: Norberg B. Umeå-a society model. (culture) Rondel 2002;10. http://www.rondellen.net.

8 Lökk J, Nilsson M, Norberg B, et al. Controversies around vitamin B12 in Sweden. Attitudes and values behind clinical decision-making in primary health care 1996. Hematology 1997;2:341-50.

9 Lökk J, Nilsson M, Norberg B, et al. Shifts in B12 opinions in primary health care of Sweden. Scand J Public Health 2001;29:122-8.

10 Lökk J, Nilsson M, Norberg B, et al. Vitamin B12 in primary health care and geriatrics. Attitudes, knowledge, competence. Int J Geriatr Psychiatry 2001;17:987-92.

11 Nilsson M, Lökk J, Norberg B, et al. Sex differences in cobalamin (vitamin B12) opinions of Swedish physicians. Nord J Psychiatry 2002;56:299-303.

12 Shenkin BN. Politics and medical care in Sweden: the seven crowns reform. N Engl J Med 1973;288:555-9.

13 Carder M, Klingberg B. Towards a salaried medical profession: How "Swedish" was the seven crowns reform? In: Heidenheimer AJ, Elvander M, eds. The shaping of the Swedish health system. London: Croom Helm, 1980:143-72.

14 Walraven C van, Austin P, Naylor CD. Vitamin B12 injections versus oral supplements. How much money could be saved by switching from injections to pills? Can Fam Physician $2001 ; 47: 79-86$.

15 Lederle FA. Oral cobalamin for pernicious anemia: Back from the verge of extinction. J Am Geriatr Soc 1998;46:1125-7.

16 Björkegren K. Studies on vitamin B12 and folate deficiency markers in the elderly. A population-based study (Dissertation). Uppsala: Uppsala University, 2003

17 Sandström H, Norberg B, Rudolphi O, et al. Cobalaminopenia in a postindustrial society: Minimal incidence, age distribution, and differences by sex. Curr Ther Res 1996;57:599-605.

18 Habermas J. On the pragmatics of communication. Cambridge: Polity Press, 1999. 